\title{
Estádios no caminho da vida: aos que se foram e nunca estiveram tão presentes entre nós
}

\author{
Prof. Dr. HÉlio ARThur Reis IrigaraY ${ }^{1}$ \\ PROF. DR. FABRICIO STOCKER ${ }^{2}$ \\ 1 Fundação Getulio Vargas (FGV EBAPE) / Escola Brasileira de AdMinistração Pública e de EMPreSAS, Rio de JANEIRO - RJ, BRASIL \\ ${ }^{2}$ Fundação Getulio VARgas (FGV) / CADERnOS EBAPE.BR, RIO DE JANEIRO - RJ, BRASIL
}

As conferências acadêmicas são momentos especiais (por que não dizer mágicos?) nos quais temos a possibilidade de apresentar nossas pesquisas, debatendo ideias com colegas que, afortunadamente, nem sempre compartilham dos mesmos olhares ontológicos e escolhas epistemológicas.

Como na primeira seção do livro Estádios no caminho da vida, na qual Kierkegaard alude ao de Platão, as conferências acadêmicas também são como um banquete, durante o qual cada convidado compartilha sua visão sobre o amor - no caso, à ciência.

A rigor, esse é o fundamento da teoria dos três estágios ou modos de existência propostos por Kierkegaard - o estético, o ético e o religioso -, além das duas áreas limítrofes: a ironia e o humor.

Desde o ano passado, nossos encontros acadêmicos têm sido virtuais. Entretanto, o último EnANPAD foi, particularmente, o mais difícil e doloroso para muitos de nós, não só pelo distanciamento físico, mas por termos deparado com cadeiras e espaços vazios, deixados por companheiros de academia que não puderam estar mais conosco.

Perdermos abraços, trocas, afeto. O mundo ficou mais triste, mais pobre.

A dor causada pelas ausências de Cristiano, Eduardo, Sidinei, Zélia, entre tantos outros, se fez presente em silêncios, pausas, lágrimas, durante muitas reuniões de grupos de trabalho, divisões e painéis.

Como nos estádios do caminho da vida, num primeiro momento, vivenciamos o estético, no qual nos sentimos abandonados ao imediatismo de uma sensação de abandono e injustiça. Nesse estádio estético, vivemos momentos de dúvida e desespero, como os representados por Fausto e pelo judeu errante Ahasverus.

A dor pelas perdas, que dilacerava nossas almas, paradoxalmente nos fortaleceu, como indivíduos e como grupo. Submetemo-nos à lei moral, elemento central do estádio ético, e optamos por nós mesmos. Como o marido fiel, da alegoria usada pelo filósofo dinamarquês, buscamos um modo de viver a vida que fosse percebido como correto. Renunciamos ao prazer e ordenamos nossas vidas em função dos nossos deveres acadêmicos e profissionais, afinal "a esfera ética é uma esfera de transição, que todavia não é atravessada de uma vez por todas" (Kierkegaard, 2005, p. 693).

Talvez agora só nos reste buscar atingir o estádio religioso, o ponto mais alto ao qual podemos chegar, quando deparamos com uma escolha cuja implicação resulta numa finalidade maior.

Kierkegaard buscou desvelar todas as possibilidades com as quais nos defrontamos ao longo de nossa existência. Vemo-nos forçados a fazer escolhas em função desses três estádios, que guardam diferenças qualitativas entre si e são ordenados por paixões e valores singulares. $O$ indivíduo que está num estádio só permanece nele por uma escolha existencial. Do mesmo modo, ele é livre para optar por outro estádio. Nas palavras de Kierkegaard: "A história da vida individual se desenrola em um movimento que vai de estádio em estádio e cada um é posto por um salto" (Kierkegaard, 2005, p. 210).

Então, que sejamos e sigamos fortes, construindo uma ciência aplicada e engajada.

Assim, apresento os artigos que compõem esta quarta edição de 2021 dos Cadernos EBAPE.BR. Iniciaremos o número com uma pensata escrita por Ana Heloísa da Costa Lemos e Aline Mendonça Fraga sobre nosso companheiro de academia Sidinei Rocha-de-Oliveira, que nos deixou às vésperas do EnANPAD. 
A seguir, segue um artigo de apresentação produzido em coautoria com Jefferson Rodrigues Pereira e Kely César Martins de Paiva, intitulado "'Trabalho Sujo', significado, sentido e identidade: proposição de análise integrada e perspectivas de pesquisas", cujo objetivo foi apreender as possíveis relações entre significado, sentido e identidade do trabalho, considerando ambiguidades e paradoxos que permeiam certas ocupações na sociedade brasileira.

Em "A organização da prática dos roteiros turísticos no turismo receptivo", Talita Almeida Fernandes, Alfredo Rodrigues Leite da Silva e Filipe Cabacine Lopes Machado se dedicam a compreender o organizar da prática de roteiros turísticos com base na epistemologia prática de Theodore Schatzki.

Já Mel Girão e Erik Fernandes focam em responder à instigante pergunta "O que resta de marketing para o Chief Marketing Officer?", valendo-se do método de revisão sistemática da literatura, trazendo uma importante discussão para a área de marketing.

No artigo "As relações de gênero no contexto socioeconômico e cultural brasileiro: estudo com mulheres motoristas de aplicativos de mobilidade urbana", Ana Paula de Oliveira Amaral Colodetti e Marlene Catarina de Oliveira Lopes Melo analisam como as relações de gênero e o contexto socioeconômico e cultural brasileiro são percebidos por mulheres motoristas de aplicativos de mobilidade urbana em sua atuação profissional e no ambiente de trabalho.

As possibilidades de estreitamento das relações entre universidades e empresas por meio dos Centros de Pesquisa Universitária são o objeto da pesquisa de José da Assunção Moutinho e Roque Rabechini Junior, chamada "Centro de pesquisa universitária: caracterização do ambiente de pesquisa".

"Quando a teoria dos stakeholders encontra a teoria da justificação: uma proposta de interseção" é o título do artigo de Helna Almeida de Araujo Góes, Germano Glufke Reis e Gustavo Abib, um ensaio que lança luz sobre a identificação e o envolvimento dos stakeholders, bem como sobre a complementariedade entre as abordagens teóricas.

Com o objetivo de compreender como se manifesta o misbehavior de empreendedores associado às práticas de sonegação fiscal em micro e pequenas empresas, sob a óptica do jeitinho brasileiro, Marina Emanuelli Belo, Thiago Cavalcante Nascimento e Andréa Torres Barros Batinga de Mendonça nos brindam com "Misbehavior empreendedor associado às práticas de sonegação fiscal".

"O impacto da diversidade das gerações na confiança dentro das empresas", escrito por Carmen Pires Migueles, Marco Tulio Fundão Zanini, Juliana Carvalho e Fernando Filardi, aborda as causas das diferenças geracionais no trabalho e seu impacto na propensão para a confiança.

Já no artigo "Davi versus Golias - A resistência dos não-humanos no processo de tradução: o caso do desinteressamento do novo coronavírus", Eduardo Guedes Villar, Karina De Déa Roglio, Marcos Vinícius Pereira Correa e Rodrigo Seefeld, com base na sociologia da tradução, estudam o caso extremo do novo coronavírus para explorar o papel dos não-humanos nos processos relacionais.

Com o objetivo de analisar a relação entre a TIC e a funcionalidade dos bancos brasileiros entre 1995 e 2016, Luiz Paulo Fontes de Rezende, Fernanda Faria Silva e Marco Crocco escreveram "Tecnologia de comunicação e informação no setor bancário brasileiro: a funcionalidade importa?"

Em "E Mintzberg descobriu o Brasil: a internacionalização de um programa de mestrado executivo", Ana Christina Celano Teixeira, Sergio Wanderley, Ana Beatriz Moraes e Bianca Sá adotam uma perspectiva crítica para investigar se o IMPM, um programa de mestrado oferecido por uma instituição de ensino superior brasileira em parceria com outras estrangeiras, privilegia o ponto de vista anglo-saxão ou não.

Andreia Maria Berto, Rolf Hermann Erdmann e Vivian Osmari Uhlmann apresentam uma teoria substantiva que se propõe a explicar como interagem e que fatores influenciam os elementos envolvidos no processo de implantação, manutenção e evolução da acreditação hospitalar, no artigo chamado "Proposição de uma teoria substantiva para o processo de acreditação hospitalar: o modelo 'comprometimento com o cuidado".

Ao analisar a relação tempo-espaço e suas transformações longitudinais, bem como as dinâmicas objetivas e subjetivas entre sujeito e contexto, Alexandre Dal Molin Wissmann, Jhony Pereira Moraes, Arthur Gehrke Martins Andrade e Jair Jeremias 
Junior investigam a carreira no batuque de 2 pessoas de diferentes gerações que vivem essa trajetória, em "Trabalhadores do batuque: a carreira numa religião afro-gaúcha".

"Improvisação organizacional: desafios e perspectivas para o ensino-aprendizagem em administração" é um artigo escrito por Fernanda Paquelet Moreira Barbosa e Eduardo Davel, com o objetivo de sistematizar os avanços na produção acadêmica acerca de improvisação organizacional e discutir sua integração no ensino-aprendizagem da administração.

Em “Um estudo pós-colonial, com o uso da semiótica, sobre capas de livros clássicos editados no Brasil e nos Estados Unidos", Mariana Luz Eiras Queiroz, Marcus Wilcox Hemais e Luís Alexandre Pessôa buscam analisar como são representados o Norte e o Sul globais no projeto gráfico de capas de livros clássicos brasileiros e estadunidenses.

Por sua vez, Ana Paula Paes de Paula e Ketlle Duarte Paes no estudo "Fordismo, pós-fordismo e ciberfordismo: os (des)caminhos da Indústria 4.0", buscam abordar a Indústria 4.0 como o cerne de um novo paradigma de produção, evidenciando como se dá a radicalização dos processos de automação da produção e de inserção da inteligência artificial nos processos decisórios.

Boa leitura a todos!

Prof. Dr. Hélio Arthur Reis Irigaray

EDITOR-CHEFE

PROF. DR. FABRICIO STOKER

EDITOR ADJUNTO 


\section{REFERÊNCIA}

Kierkegaard, S. (2005). In Vino Veritas. Lisboa, Portugal: Antógona.

Prof. Dr. Hélio Arthur Reis Irigaray

ORCID: https://orcid.org/0000-0001-9580-7859

Doutor e Mestre em Administração de Empresas pela FGV EAESP e PUC-Rio, respectivamente; Bacharel em Economia pela University of Northern Iowa, EUA; Professor adjunto da FGV EBAPE e do programa CIM - Corporate International Masters, da Georgetown University, Washington, EUA; Líder do tema Diversidade e Relações de Trabalho, na linha de Gestão de Trabalho (ANPAD). E-mail: helio.irigaray@fgv.br

\section{Prof. Dr. Fabricio Stocker}

ORCID: https://orcid.org/0000-0001-6340-9127

Doutor em Administração pela FEA/USP e Ph.D. in Management pela Erasmus University of Rotterdam; Pesquisador visitante na University of Amsterdam; Mestre em Administração pela UFPR e formação executiva pela FGV pela London Business School; Economista e Administrador; Professor na FGV na graduação on-line, MBA e Pós-Graduação; Atua como Editor Adjunto no Cadernos EBAPE.BR (FGV). E-mail: fabricio.stocker@fgv.br 